\title{
Acute Shift in Glutamate Concentrations Following Experimentally Induced Panic with Cholecystokinin Tetrapeptide-A 3T-MRS Study in Healthy Subjects
}

\author{
Peter Zwanzger*, I,4, Maxim Zavorotnyy ${ }^{\text {I,4 }}$, Elena Gencheva', Julia Diemer', Harald Kugel ${ }^{2}$, Walter Heindel ${ }^{2}$, \\ Tillmann Ruland', Patricia Ohrmann', Volker Arolt', Katharina Domschke ${ }^{1,3}$ and Bettina Pfleiderer ${ }^{2}$ \\ 'Mood and Anxiety Disorders Research Unit, Department of Psychiatry and Psychotherapy, University of Muenster, Muenster, Germany; \\ ${ }^{2}$ Department of Clinical Radiology, University of Muenster, Muenster, Germany; ${ }^{3}$ Department of Psychiatry, University of Wuerzburg, \\ Wuerzburg, Germany
}

According to preclinical studies, glutamate has been implicated in the pathogenesis of anxiety. In order to elucidate the role of glutamate in anxiety and panic in humans, brain glutamate + glutamine (Glx) levels were measured during cholecystokinin-tetrapeptide (CCK-4)induced panic using magnetic resonance spectroscopy (MRS). Eighteen healthy subjects underwent a CCK-4 challenge. MR spectra were obtained from the anterior cingulate cortex (ACC) using a single voxel point-resolved spectroscopy method and analyzed using LCModel. A combined fitting of Glx was performed. Panic was assessed using the Acute Panic Inventory (API) and Panic Symptom Scale (PSS) scores. Moreover, hypothalamic-pituitary-adrenal axis stimulation was monitored throughout the challenge. There was a significant panic response following CCK-4 as revealed by a marked increase in both the panic scores (API: F(I,I7) $=149.41 ; p<0.0001$; PSS: $F(I, I)=88.03 ; p<0.000 I)$ and heart rate $(H R: F(I, I 7)=72.79 ; p<0.000 I)$. MRS measures showed a significant increase of brain $\mathrm{Gl} /$ creatine $(\mathrm{Gl} / \mathrm{Cr}$ ) levels peaking at $2-10 \mathrm{~min}$ after challenge $(\mathrm{F}(\mathrm{I}, \mathrm{I7})=15.94 ; p=0.00 \mathrm{I})$. There was also a significant increase in CCK-4-related cortisol release $(F(6, I)=8.68 ; p=0.002)$. Finally, significant positive correlations were found between baseline $\mathrm{Gl} / \mathrm{Cr}$ and both $\mathrm{API}_{\max }(r=0.598 ; p=0.009)$ and maximum heart rate $\left(H R_{\max }\right)$ during challenge $(r=0.519 ; p=0.027)$. Our results suggest that CCK-4-induced panic is accompanied by a significant glutamate increase in the bilateral ACC. The results add to the hypothesis of a disturbance of the inhibitory-excitatory equilibrium and suggest that apart from static alterations rapid and dynamic neurochemical changes might also be relevant for the neural control of panic attacks.

Neuropsychopharmacology (2013) 38, 1648-1654; doi:I0.1038/npp.2013.6I; published online 17 April 2013

Keywords: panic attacks; anxiety; glutamate; CCK-4; magnetic resonance spectroscopy; anterior cingulate cortex

\section{INTRODUCTION}

With a lifetime prevalence of $3.5 \%$, panic disorder (PD) represents one of the most frequent psychiatric disorders (Kessler et al, 1998; Roy-Byrne et al, 2000). The disorder is characterized by the occurrence of sudden, unexpected panic attacks, which are accompanied by several somatic symptoms such as palpitations, dyspnea, dizziness, headache, nausea, and others (White and Barlow, 2002). The etiology is complex and comprises both neurobiological and psychosocial aspects (White and Barlow, 2002; Gorman et al, 2000; Martin et al, 2010).

*Correspondence: Professor P Zwanzger, Mood and Anxiety Disorders Research Unit, Department of Psychiatry and Psychotherapy, University of Muenster, Albert-Schweitzer-Strasse II, 49 I 49 Muenster, Germany, Tel: +49 25। 83566 13, Fax: +49 25। 83566 12, E-mail: zwanzger@ukmuenster.de

${ }^{4}$ These authors contributed equally to this work.

Received 9 November 2012; revised 5 February 2013; accepted 8 February 2013; accepted article preview online 5 March 2013
There is increasing evidence that an excitatory-inhibitory dysbalance might have an important role in the pathophysiology of $\mathrm{PD}$. In this regard, several studies point towards a role of the gamma-amino-butyric acid (GABA) system, suggesting a decreased GABAergic tone as a key factor for the pathogenesis of panic and anxiety. Investigations using positron-emission tomography have shown that patients with $\mathrm{PD}$ have a decreased sensitivity of $\mathrm{GABA}_{\mathrm{A}}$ receptors (Malizia et al, 1998; Hasler et al, 2008). Moreover, a decrease in cortical GABA concentrations has been demonstrated in studies using magnetic resonance spectroscopy (MRS) (Goddard et al, 2001). Alterations have also been found in concentrations of neuroactive steroids, which are known to act as allosteric modulators at the $\mathrm{GABA}_{\mathrm{A}}$ receptor (Strohle et al, 2002). Finally, the well-known rapid and strong anxiolytic effects of benzodiazepines are mediated by the benzodiazepine-binding site at the $\mathrm{GABA}_{\mathrm{A}^{-}}$ receptor (Ballenger et al, 1988; Zwanzger and Rupprecht, 2005; Domschke and Zwanzger, 2008).

Glutamate represents the most important excitatory neurotransmitter and deploys its excitatory action via 
binding at the $N$-methyl-D-aspartate (NMDA) and the alpha-amino-3-hydroxy-5-methyl-4-isoxazole-propionic acid receptor, which are predominantly located in the cortical and limbic structures (Bergink et al, 2004; Bliss and Collingridge, 1993). According to preclinical studies, glutamatergic signal transduction in the lateral amygdala has a significant role in fear-conditioning and extinction (Rogan et al, 1997). In humans, so far only few studies have looked at the possible role of glutamate in anxiety disorders. With regard to pharmacological intervention, the following studies point towards anxiolytic effects of glutamate antagonists: In patients with major depression and bipolar disorder, beneficial effects have been observed after treatment with NMDA antagonists (Berman et al, 2000). Moreover, positive results have been reported in experimentally induced anxiety using beta-carboline after treatment with the glutamate antagonist riluzole (Stutzmann et al, 1989).

Experimental panic induction has been established as a valid and reliable paradigm for the assessment of neurobiological correlates in panic attacks, anxiety, and acute stress. Among the available panicogenic agents, the neuropeptide cholecystokinin-tetrapeptide (CCK-4) has been shown to induce panic attacks both in patients with $\mathrm{PD}$ and in healthy volunteers (Zwanzger et al, 2012). Moreover, panic symptoms elicited by CCK-4 are attenuated after pharmacological treatment: Several studies have shown that treatment with antidepressants, which currently represent first-line treatment for $\mathrm{PD}$, lead to a reduction of panic experimentally induced by CCK-4 (Bradwejn and Koszycki, 1994; Shlik et al, 1997). Similarly, anxiolytics such as the benzodiazepine alprazolam ameliorate CCK-4induced panic attacks in healthy volunteers (Zwanzger et al, 2003). Such effects have also been observed in larger samples using XBD173, a ligand of the translocator (TPSO) protein (Rupprecht et al, 2009), which recently has been identified as a possible new treatment target for anxiety (Rupprecht et al, 2010; Nothdurfter et al, 2012). As shown by neuroimaging studies, experimentally induced panic attacks are accompanied by a significant activation of neuroanatomical key areas responsible for the processing of fear and anxiety, such as the amygdala, hippocampus, insula, and the anterior cingulate cortex (ACC) (Schunck et al, 2006; Eser et al, 2009). Finally, the ACC has been identified as a major target for benzodiazepines in CCK-4induced panic (Leicht et al, 2013).

In order to further elucidate the role of an excitatoryinhibitory dysbalance in the pathogenesis of panic and anxiety, brain glutamate + glutamine (Glx) levels in the ACC were assessed during CCK-4-induced panic attacks by means of 3 Tesla proton magnetic resonance spectroscopy (3T-MRS). For correlation with subjects' individual stress response, hypothalamic-pituitary-adrenal (HPA) axis activity was assessed by monitoring cortisol levels along with MRS measurements during the entire procedure.

\section{MATERIALS AND METHODS}

\section{Subjects}

Eighteen healthy right-handed male subjects (mean age $26.9 \pm 4.5$ years) were investigated. Subjects were recruited via advertising. Any history of mental disease was excluded before the study using the structured Mini International Neuropsychiatric Interview (Sheehan et al, 1997). Any somatic disease was ruled out by means of routine laboratory testing and physical examination. All subjects had to be free of any medication. Any drug intake was ruled out by urine toxicology screening. The protocol was approved by the Ethics Committee of the Medical Faculty at the University of Muenster, Muenster, Germany. Written informed consent was obtained from all the subjects after the procedure had been fully explained.

\section{CCK-4 Challenge Procedure}

Subjects were instructed to fast $10 \mathrm{~h}$ before the CCK-4 challenge. On the day of the CCK-4 challenge, an intravenous catheter was inserted into a forearm vein $60 \mathrm{~min}$ before MRS measure after subjects had been laid down in the scanner. After baseline $(-5 \mathrm{~min}) \mathrm{MRS}$ scan, $50 \mu \mathrm{g}$ CCK-4 (Merck, Switzerland) were administered intravenously in a bolus injection.

Panic symptoms were assessed using the Acute Panic Inventory (API) (Dillon et al, 1987) and a DSM-IV-derived Panic Symptom Scale (PSS) (Bradwejn and Koszycki, 1994) at baseline shortly before CCK-4 injection ( $0 \mathrm{~min}$ ) and $5 \mathrm{~min}$ after CCK-4 administration. Heart rate (HR) was recorded at baseline and peak levels after CCK-4 administration. For a categorical analysis of the panic response, a 'panic attack' was defined as a API total score $\geqslant 20$ and an increment of $\geqslant 14$ points above the pre-injection score.

Blood samples for determination of plasma cortisol and adrenocorticotropic hormone $(\mathrm{ACTH})$ were drawn by a technical assistant in the scanner room shortly before CCK-4 injection ( $-1 \mathrm{~min})$ and continuously throughout the challenge procedure at $5,10,15,20,30$, and $60 \mathrm{~min}$. The samples were placed on ice and stored at $-80{ }^{\circ} \mathrm{C}$ after immediate plasma separation. Cortisol was quantified using a commercial enzyme immunoassay (ELISA) (CortisolELISA, IBL International GmbH, Hamburg, Germany). The lower detection limit was $8.28 \mathrm{nmol} / 1$. Intra- and inter-assay coefficients of variation were 2.4 and $6.4 \%$, respectively.

\section{Magnetic Resonance Spectroscopy $\left({ }^{1} \mathrm{H}-\mathrm{MRS}\right)$}

The magnetic resonance imaging protocol included T1-weighted 3D-spoiled gradient echo acquisition of the whole brain and T2 and proton density-weighted fast spin echo sequences in transaxial and coronal orientation. For the MRS measurements, a single voxel point-resolved spectroscopy method $(\mathrm{TE}=32 \mathrm{~ms}$, repetition time $=2134 \mathrm{~ms}$; voxel size $=35 \times 15 \times 15 \mathrm{~mm}^{3}=7.875 \mathrm{~cm}^{3}$, number of scans $=128$ ) at $3 \mathrm{~T}$ (Gyroscan Intera Philips, Best, NL, USA) was used. Time resolution of the MRS series was $5 \mathrm{~min}$. Six subsequent MRS spectra were acquired in total: $5 \mathrm{~min}$ before challenge (baseline, T0), with CCK-4 injection (T1), 5 (T2), 10 (T3), 15 (T4), and 20 (T5) min after injection. For statistical analysis, maximum values compared with baseline were used to test for potential influences of experimentally induced panic on neurochemical parameters. According to previous imaging studies showing CCK4-induced panic to be accompanied by activation in the 
ACC (Schunck et al, 2006; Eser et al, 2009), this region was chosen as the target area.

Voxel position was assigned according to Creutzfeldt (1983) to include Brodmann area 24/32 (Economo $\mathrm{L}_{\mathrm{A}} / \mathrm{FDL}$ ) as described previously (Pfleiderer et al, 2002; see Figure 1). To assure high intraindividual reproducibility, scans were referenced to readily identifiable anatomic landmarks within the brain; the base of the voxel was aligned perpendicular to the tip of the genu corporis callosi (Pfleiderer et al, 2003).

Postprocessing was standardized using the LCModel program package (Provencher, 1993), with zero filling, Fourier transformation and automated phase, baseline, and eddy current correction. After postprocessing of the spectra, metabolite concentrations were calculated using the frequency domain-fitting procedure provided by LCModel. Due to the overlapping resonances of glutamate, glutamine, and GABA, only a combined fitting of Glx was performed. For robustness of results, only metabolite information with the fitting error (\% SD) of $<20 \%$ SD was included in the final analysis. The contribution of altered GABA levels may still have influenced our data. However, GABA concentration, in general, is much lower than combined Glx (Sanacora et al, 1999). Also, Glx signal is mostly dominated by glutamate (Auer et al, 2000).

\section{Statistics}

To facilitate the comparison of Glx levels at baseline and after CCK-4 injection, Glx values were normalized to creatine $(\mathrm{Cr})$ and $\mathrm{Glx} / \mathrm{Cr}$ values. Maximal deviation from baseline levels before CCK-4 administration in percentage was calculated $\left(\mathrm{p}\left(\mathrm{Gl}_{[\max ]}\right)\right)$.

To analyze brain metabolic changes, maximum concentrations of $\mathrm{Glx} / \mathrm{Cr}$ after CCK-4 injection were compared with baseline using an analysis of variance (ANOVA) with repeated-measures design. Time (baseline and post-CCK-4 injection) was used as a within-subject factor. A forward linear regression analysis was used to evaluate the impact of glutamatergic baseline concentration on the extent of Glx/ $\mathrm{Cr}$ increase. Subjective panic reaction (API, PSS) following CCK-4 challenge and maximum $\mathrm{HR}$ were analyzed in the same manner. Stimulation of HPA axis after panic induction by CCK-4 was analyzed observing the time course of cortisol/ACTH concentrations as well as comparing baseline and peak hormone levels using an ANOVA with repeated measures design with time (minutes after challenge) as a within subject factor in both cases. To test for significant correlations between changes in $\mathrm{Glx} / \mathrm{Cr}$ levels and behavioral data, Pearson correlations were performed. Results are expressed as mean \pm SD. $\alpha=0.05$ was set as the nominal level of significance. The Statistical Package for Social Sciences SPSS (PASW 18) was used for statistical analyses (PASW 18, now IBM, Armonk, NY, USA).

\section{RESULTS}

Baseline and maximum levels after the CCK-4 challenge (post challenge) of behavioral data, HR, cortisol/ACTH and MRS measures are shown in Table 1.

Panic challenge with CCK-4 was followed by a rapid and significant increase in panic symptoms as revealed by significant changes in both the API ( $\mathrm{API}_{\max } v s$ API baseline; $\mathrm{F}(1,17)=149.41 ; p<0.0001)$ and the PSS score $\left(\mathrm{PSS}_{\max } v s\right.$ PSS baseline; $\mathrm{F}(1,17)=88.03 ; p<0.0001)$. Experimentally induced panic was furthermore accompanied by a significant increase in $\operatorname{HR}(\mathrm{F}(1,17)=72.79 ; p<0.0001)$. In all, 15 out of 18 subjects fulfilled the criteria of a panic attack.

Moreover, MRS measurements indicated an increase of brain $\mathrm{Glx} / \mathrm{Cr}$ concentrations. Mean $\mathrm{Glx} / \mathrm{Cr}$ concentrations at the respective time points are illustrated in Figure 2. For statistical analysis, individual peak values throughout the whole challenge procedure were compared with baseline levels. Repeated-measures ANOVA revealed the significance of the change $(\mathrm{F}(1,17)=15.94 ; p=0.001)$. A forward linear regression analysis indicated that the glutamatergic baseline concentration seems to mainly determine the extent of percentage of $\mathrm{Glx} / \mathrm{Cr}$ increase $(\mathrm{F}(1,16)=19.64, p<0.0001)$.

There was also a significant increase in CCK-4-related HPA axis stimulation mirrored by a significant effect on plasma cortisol levels 10-15 min after CCK-4 administration. Data for cortisol were missing in one subject. ANOVA for repeated measures revealed a significant effect $(\mathrm{F}(6,10)=8.68 ; p=0.002)$. There was also a trend towards a

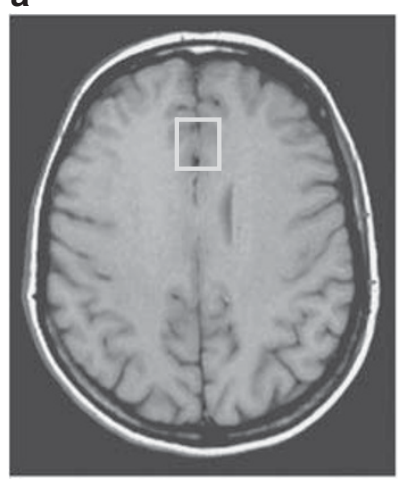

b

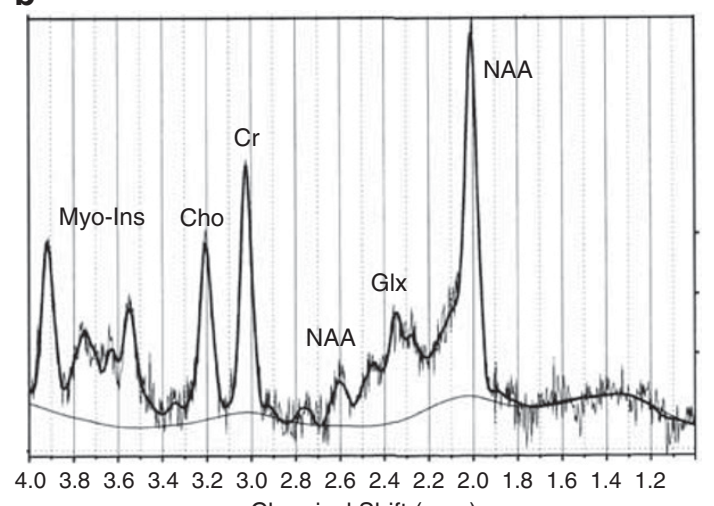

Chemical Shift (ppm)

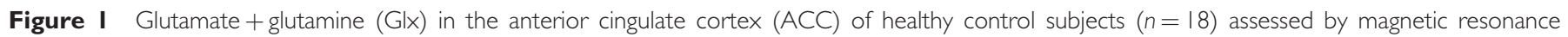

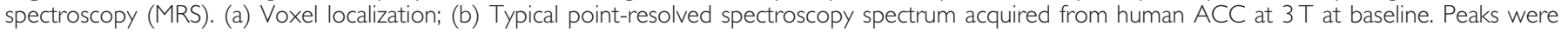
assigned as follows: N-acetyl aspartate (NAA), total $\mathrm{Cr}$, total choline (Cho), Glx, and Myo-Inositol (Myo-Ins). 
Table I Baseline and Peak Values of Behavioral Data, Heart Rate, Cortisol/ACTH and MRS Measures Throughout the Entire Challenge Procedure

\begin{tabular}{|c|c|c|c|c|}
\hline & Baseline (mean \pm SD) & Peak values (mean \pm SD) & $\mathbf{F}$ & $P$-value \\
\hline Glx/Cr (IU) & $2.25 \pm 0.24$ & $2.62 \pm 0.27^{\mathrm{a}}$ & 15.94 & 0.001 \\
\hline API & $4.28 \pm 5.14$ & $31.22 \pm 10.54$ & $|49.4|$ & $<0.001$ \\
\hline PSS & $3.00 \pm 3.80$ & $26.28 \pm 10.93$ & 88.03 & $<0.001$ \\
\hline $\mathrm{HR}(\mathrm{bpm})$ & $65.94 \pm 10.32$ & $116.94 \pm 22.76$ & 72.79 & $<0.00$ I \\
\hline Cortisol (nmol/l) & $121.78 \pm 56.20$ & $165.87 \pm 52.73$ & 29.41 & $<0.001$ \\
\hline
\end{tabular}

Abbreviations: API, Acute Panic Inventory; bpm, beats per minute; Glx/Cr, glutamate + glutamine/creatine; HR, heart rate; PSS, Panic Symptom Scale. Repeated measures ANOVA, significance level at $p<0.05$. ${ }^{a}$ Mean of individual maximum Glx/Cr levels (TI-T5).

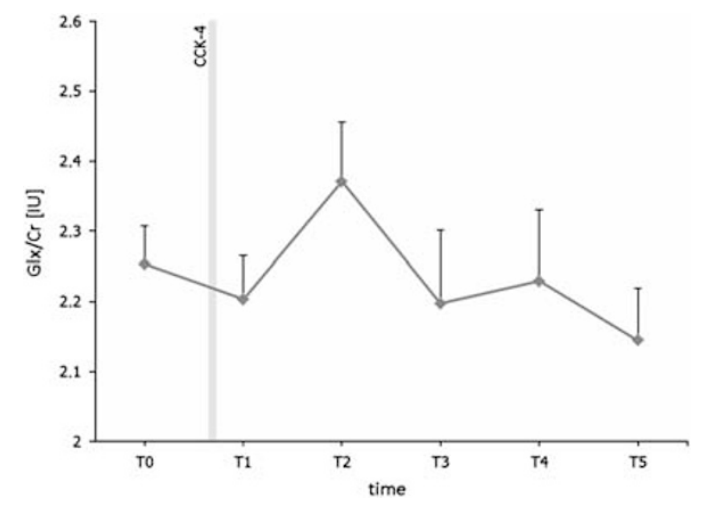

Figure 2 Time course of $\mathrm{G} / x / \mathrm{Cr}(\mathrm{IU})$ levels (mean \pm SEM) throughout the CCK-4 challenge. Levels provided represent the respective mean concentrations for each time point of MRS scans (T0-T5).

significance for increases in ACTH plasma concentrations $5 \mathrm{~min}$ after CCK-4 challenge $(\mathrm{F}(6,11)=2.95 ; p=0.057)$. Correlation analyses were carried out in order to detect a possible relationship between glutamate metabolism and panic symptoms. Analyses showed a significant positive correlation between baseline $\mathrm{Glx} / \mathrm{Cr}$ concentrations and $\mathrm{API}_{\max }(r=0.598 ; p=0.009)$ (Figure 3$)$. No effects were found for the correlation between maximum $\mathrm{Glx} / \mathrm{Cr}$ concentrations and API $I_{\max }$. There was also a significant positive correlation between baseline $\mathrm{Glx} / \mathrm{Cr}$ concentrations and $\mathrm{HR}_{\text {max }}(r=0.519 ; p=0.027)$. There was also a trend towards significance for a correlation between peak cortisol levels and percentage of $\mathrm{Glx} / \mathrm{Cr}$ increase $(r=0.445 ; p=0.065)$.

\section{DISCUSSION}

The aim of this study was to investigate brain Glx concentrations during experimental panic induction with CCK-4. The main finding was that CCK-4-induced panic was accompanied by a rapid and significant increase of Glx concentrations in the ACC. Moreover, panic was associated with a marked increase in the HPA axis stimulation as described previously (Kellner et al, 2000; Koszycki et al, 1998; Zwanzger et al, 2003).

Overall, with regard to behavioral effects observed after CCK-4 administration, the present results are in accordance

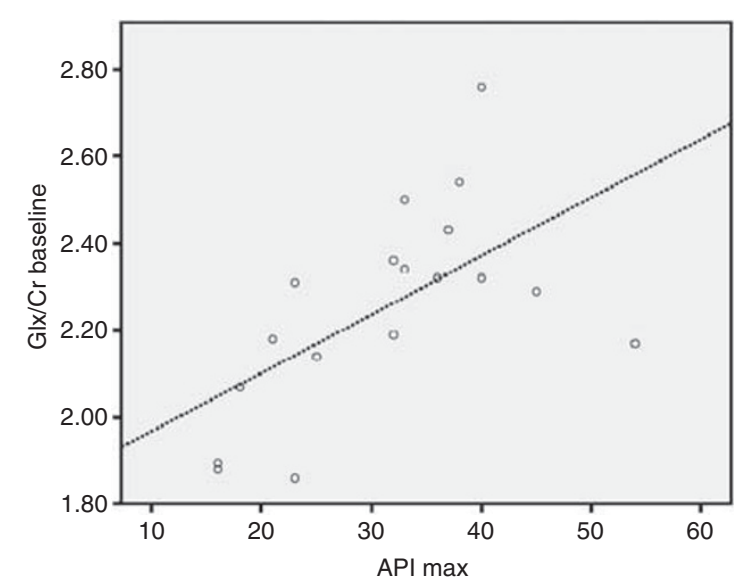

Figure 3 Significant correlation between baseline concentrations of glutamate + glutamine/creatine $(\mathrm{G} / \times / \mathrm{Cr})$ and maximum Acute Panic Inventory (API) panic score (API max); $r=0.598 ; p=0.009$.

with the extensive body of literature on the panicogenic effects of CCK-4 (see Zwanzger et al, 2012).

Our results are in line with available data on glutamate metabolism in anxiety disorders. In patients with social anxiety disorder, glutamate levels were found to be significantly elevated in the ACC compared with controls (Phan et al, 2005). Also in other disorders with dysbalanced impulsivity such as in borderline personality disorder, an increase in ACC glutamate levels has been described (Hoerst et al, 2010). In line with our results, glutamate concentrations in the frontal cortex of healthy subjects might depend on anxiety levels as revealed by a study of Grachev and Apkarian (2000). The authors showed that subjects with high levels of anxiety display an increased overall chemical activity in the frontal cortex by $>30 \%$ compared with subjects with low levels of anxiety. However, no significant correlation between maximum Glx and panic scores has been found in our study. Instead, a significant positive correlation between baseline Glx and panic response to CCK-4 was detected. It might be discussed whether in view of higher baseline levels in some subjects a possible ceiling effect may have masked a potential correlation.

From a preclinical point of view, the idea of increased glutamate in anxiety would be in line with the observation that excessive glutamate release within the limbic system is associated with fear-related learning (Walker and Davis, 
2002). Intriguingly, decreased ACC glutamate concentrations in healthy subjects have been found to be associated with high levels of sensation-seeking behavior (Gallinat et al, 2007), which usually goes along with high risk taking and low levels of anxiety-related behavior according to preclinical studies (Blanchard et al, 2009).

The fact that Glx concentrations show a fast and immediate increase following experimental panic induction suggests that apart from static alterations in glutamatergic neurotransmission outlined above rapid and dynamic neurochemical changes might also be important for the neural control of acute anxiety and panic attacks. In similarly designed studies using the CCK- 4 paradigm, an immediate shift of $\mathrm{GABA}_{\mathrm{A}}$-receptor modulating neuroactive steroids after experimentally induced panic was observed in patients with PD (Strohle et al, 2003) and healthy volunteers (Eser et al, 2005), with the latter study suggesting that the significant increase of $3 \alpha-5 \alpha$-tetrahydrodeoxycorticosterone $(3 \alpha, 5 \alpha-$ THDOC $)$ as a positive allosteric modulator of the $\mathrm{GABA}_{\mathrm{A}}$-receptor might contribute to the termination of the anxiety response to CCK-4 (Eser et al, 2005). According to Salt and Eaton (1996), GABAergic and glutamatergic neurotransmission seems to be modulated by presynaptic metabotropic glutamate (mGlu) autoreceptors. Moreover, it has also been suggested that neurosteroids, synthesized in cortical glutamatergic neurons, may exert GABAergic activity through autocrine (targeting postsynaptic receptors at the same neuron) and/or paracrine (targeting receptors at distal neurons) mechanisms (Rupprecht et al, 2010). Finally, GABA released from GABAergic interneurons targets pre-, post-, and extrasynaptic receptors at glutamatergic principal output neurons (for a review, see Rupprecht et al, 2010). Thus, our results point towards a possible functional interaction of glutamatergic neurotransmission and neuroactive steroid regulation in the experimental panic model.

However, other anxiety-provoking paradigms yielded different results. In a threat-of-shock paradigm in healthy subjects, no changes in Glx levels were discerned (Hasler et al, 2010). Instead, a marked and significant decrease in prefrontal GABA concentrations was observed (Hasler et al, 2010). However, differences in the anxiety provocation paradigm might account for diverging findings: although the study of Hasler et al (2010) investigated the aspect of anticipatory anxiety, our study investigated acute panic using a well-established pharmacological challenge procedure.

In our study, CCK-4-induced panic attacks were furthermore accompanied by a marked and significant HPA axis stimulation, which is in line with several previous reports (Kellner et al, 2000; Koszycki et al, 1998; Zwanzger et al, 2003). Although data on the relationship of glutamate and HPA axis activity in humans are scarce, some reports show that glutamate is increased in stress-related situations. In a study investigating healthy volunteers, Glx was increased in the visual cortex following vigorous physical exercise (Maddock et al, 2011). Also, preclinical studies suggest a close relationship between glutamate metabolism and stress regulation: Corticotropin-releasing hormone neurons are co-localized with vesicular glutamate transporters (Herman et al, 2000). Glutamate microinjections into the paraventricular nucleus are followed by an increase of cortisol
(Brann and Mahesh, 1997). Moreover, glutamate-induced release of corticotropin-releasing hormone and cortisol has been shown to be mediated by NMDA receptors (Brann and Mahesh, 1997). Although the correlation analysis between maximum cortisol levels and panic scores only yielded borderline significance, these results still point to a close relationship between the glutamatergic and the HPA system and thus support findings in human studies.

Our results could also have implications for treatment of anxiety. There is ample evidence for anxiolytic properties of medication targeting the glutamate system. In both the animal and human studies, anxiolytic effects have been observed after treatment with modulators of ionotropic NMDA and mGlu receptors (Riaza Bermudo-Soriano et al, 2011; Bergink et al, 2004). It has been shown that modulators of the NMDA receptor are capable of blocking extinction learning (Kaplan and Moore, 2011). Moreover, the NMDA receptor agonist D-cycloserine has been shown to enhance effects of cognitive behavioral therapy in anxiety disorders in a couple of clinical studies based on its capacity to influence memory consolidation (Otto et al, 2010; Ressler et al, 2004). With regard to mGlu receptors, anxiolytic properties have been proposed for an allosteric modulator of the mGluR2/3 receptor subtype (Krystal et al, 2010). Moreover, patients with generalized anxiety disorder reported a significant decrease in anxiety sensitivity and worry after treatment with riluzole, which decreases glutamate release (Mathew et al, 2005; Pittenger et al, 2008). Finally, anxiolytic effects of anticonvulsants have, in part, also been attributed to their effect on the glutamatergic system (Riaza Bermudo-Soriano et al, 2011).

However, the present findings have to be considered in the light of several limitations and must therefore be interpreted with caution. The sample size is relatively small and includes only males. Thus, our study does not allow for extrapolation to a female sample. Moreover, no patients were included in the study. With regard to MRS, only a combined fitting of Glx was performed. Nevertheless, as mentioned in the Methods section, the Glx signal is assumed to be mostly dominated by glutamate (Auer et al, 2000). Additionally, no placebo injection was administered. Therefore, metabolic changes due to stress and anticipatory anxiety cannot be fully excluded. Finally, the present study did not control for the genetic background, eg, variation in the NMDA 2B receptor gene (GRIN2B), which has been shown to influence ACC Glx concentration (Arnold et al, 2009). Also, smoking or smoking cessation impacting anterior cingulate proton spectroscopy glutamate levels were not considered as potentially confounding factors (Mashhoon et al, 2011).

Taken together, our results show that CCK-4-induced panic is accompanied by a marked and significant glutamate increase in the ACC. The results are in accordance with the idea of a glutamatergic dysbalance and add to the hypothesis of a disturbance of inhibitory/ excitatory mechanisms in anxiety and anxiety disorders. However, as interpretation of our data is certainly limited due to the small sample size and the lack of a patient group, more studies in larger samples of both the healthy subjects and patients, including a molecular genetic approach, are needed to further elucidate the possible role of the 
glutamatergic system in the neurobiology of panic and anxiety.

\section{ACKNOWLEDGEMENTS}

This study was supported by 'Innovative Medizinische Forschung' (IMF) of the Medical Faculty, University of Muenster, Muenster, Germany (IMF ZW 210703). Furthermore, parts of this work were supported by the Deutsche Forschungsgemeinschaft (DFG) SFB TRR 58 subproject $\mathrm{C} 1$ to $\mathrm{PZ}$ and $\mathrm{C} 2$ to $\mathrm{KD}$. Parts of this work were subject of the doctoral thesis of EG.

\section{DISCLOSURE}

All affiliations mentioned below have no relevance to the work covered in the manuscript: $\mathrm{PZ}$ has received speaker fees from Pfizer, Servier, Lilly, Astra Zeneca, and BristolMyers Squibb, he is on the advisory board of Pfizer, is a consultant for Ironwood Pharmaceuticals, and has received funding from Astra Zeneca. VA is member of advisory boards and/or gave presentations for the following companies: Astra Zeneca, Janssen-Organon, Lilly, Lundbeck, Servier, Pfizer, Otsuka, and Wyeth. He chaired the committee for the 'Wyeth Research Award Depression and Anxiety'. KD has received speaker fees from Pfizer, Lilly, and Bristol-Myers Squibb, She was a consultant for Johnson and Johnson and has received funding by Astra Zeneca. All the other authors have no conflicts of interest to declare, financial or otherwise.

\section{REFERENCES}

Arnold PD, MacMaster FP, Richter MA, Hanna GL, Sicard T, Burroughs E et al (2009). Glutamate receptor gene (GRIN2B) associated with reduced anterior cingulate glutamatergic concentration in pediatric obsessive-compulsive disorder. Psychiatry Res 172: 136-139.

Auer DP, Putz B, Kraft E, Lipinski B, Schill J, Holsboer F (2000). Reduced glutamate in the anterior cingulate cortex in depression: an in vivo proton magnetic resonance spectroscopy study. Biol Psychiatry 47: 305-313.

Ballenger JC, Burrows GD, DuPont RL Jr., Lesser IM, Noyes R Jr., Pecknold JC et al (1988). Alprazolam in panic disorder and agoraphobia: results from a multicenter trial. I. Efficacy in shortterm treatment. Arch Gen Psychiatry 45: 413-422.

Bergink V, van Megen HJ, Westenberg HG (2004). Glutamate and anxiety. Eur Neuropsychopharmacol 14: 175-183.

Berman RM, Cappiello A, Anand A, Oren DA, Heninger GR, Charney DS et al (2000). Antidepressant effects of ketamine in depressed patients. Biol Psychiatry 47: 351-354.

Blanchard MM, Mendelsohn D, Stamp JA (2009). The HR/LR model: further evidence as an animal model of sensation seeking. Neurosci Biobehav Rev 33: 1145-1154.

Bliss TV, Collingridge GL (1993). A synaptic model of memory: long-term potentiation in the hippocampus. Nature 361: 31-39.

Bradwejn J, Koszycki D (1994). Imipramine antagonism of the panicogenic effects of cholecystokinin tetrapeptide in panic disorder patients. Am J Psychiatry 151: 261-263.

Brann DW, Mahesh VB (1997). Excitatory amino acids: evidence for a role in the control of reproduction and anterior pituitary hormone secretion. Endocr Rev 18: 678-700.

Creutzfeldt OD (1983). Abgrenzung von Hirnarealen aufgrund cytoarchitektonischer Unterschiede. In: Creutzfeldt OD (eds)
Cortex Cerebri. Springer: Berlin, Heidelberg, Germany; New York, USA, pp 47-57.

Dillon DJ, Gorman JM, Liebowitz MR, Fyer AJ, Klein DF (1987). Measurement of lactate-induced panic and anxiety. Psychiatry Res 20: 97-105.

Domschke K, Zwanzger P (2008). GABAergic and endocannabinoid dysfunction in anxiety-future therapeutic targets? Curr Pharm Des 14: 3508-3517.

Eser D, di Michele F, Zwanzger P, Pasini A, Baghai TC, Schule C et al (2005). Panic induction with cholecystokinin-tetrapeptide (CCK-4) Increases plasma concentrations of the neuroactive steroid 3alpha, 5alpha tetrahydrodeoxycorticosterone (3alpha, 5alpha-THDOC) in healthy volunteers. Neuropsychopharmacology 30: 192-195.

Eser D, Leicht G, Lutz J, Wenninger S, Kirsch V, Schule C et al (2009). Functional neuroanatomy of CCK-4-induced panic attacks in healthy volunteers. Hum Brain Mapp 30: 511-522.

Gallinat J, Kunz D, Lang UE, Neu P, Kassim N, Kienast T et al (2007). Association between cerebral glutamate and human behaviour: the sensation seeking personality trait. Neuroimage 34: 671-678.

Goddard AW, Mason GF, Almai A, Rothman DL, Behar KL, Petroff OA et al (2001). Reductions in occipital cortex GABA levels in panic disorder detected with 1h-magnetic resonance spectroscopy. Arch Gen Psychiatry 58: 556-561.

Gorman JM, Kent JM, Sullivan GM, Coplan JD (2000). Neuroanatomical hypothesis of panic disorder, revised. Am J Psychiatry 157: 493-505.

Grachev ID, Apkarian AV (2000). Anxiety in healthy humans is associated with orbital frontal chemistry. Mol Psychiatry 5: 482-488.

Hasler G, Nugent AC, Carlson PJ, Carson RE, Geraci M, Drevets WC (2008). Altered cerebral gamma-aminobutyric acid type A-benzodiazepine receptor binding in panic disorder determined by [11C]flumazenil positron emission tomography. Arch Gen Psychiatry 65: 1166-1175.

Hasler G, van der Veen JW, Grillon C, Drevets WC, Shen J (2010). Effect of acute psychological stress on prefrontal GABA concentration determined by proton magnetic resonance spectroscopy. Am J Psychiatry 167: 1226-1231.

Herman JP, Eyigor O, Ziegler DR, Jennes L (2000). Expression of ionotropic glutamate receptor subunit mRNAs in the hypothalamic paraventricular nucleus of the rat. J Comp Neurol 422: 352-362.

Hoerst M, Weber-Fahr W, Tunc-Skarka N, Ruf M, Bohus M, Schmahl C et al (2010). Correlation of glutamate levels in the anterior cingulate cortex with self-reported impulsivity in patients with borderline personality disorder and healthy controls. Arch Gen Psychiatry 67: 946-954.

Kaplan GB, Moore KA (2011). The use of cognitive enhancers in animal models of fear extinction. Pharmacol Biochem Behav 99: 217-228.

Kellner M, Wiedemann K, Yassouridis A, Levengood R, Guo LS, Holsboer F et al (2000). Behavioral and endocrine response to cholecystokinin tetrapeptide in patients with posttraumatic stress disorder. Biol Psychiatry 47: 107-111.

Kessler RC, Stang PE, Wittchen HU, Ustun TB, Roy-Burne PP, Walters EE (1998). Lifetime panic-depression comorbidity in the National Comorbidity Survey. Arch Gen Psychiatry 55: 801-808.

Koszycki D, Zacharko RM, Le Melledo JM, Bradwejn J (1998). Behavioral, cardiovascular, and neuroendocrine profiles following CCK-4 challenge in healthy volunteers: a comparison of panickers and nonpanickers. Depress Anxiety 8: 1-7.

Krystal JH, Mathew SJ, D’Souza DC, Garakani A, Gunduz-Bruce H, Charney DS (2010). Potential psychiatric applications of metabotropic glutamate receptor agonists and antagonists. CNS Drugs 24: 669-693. 
Leicht G, Mulert C, Eser D, Sämann PG, Ertl M, Laenger A et al (2013). Benzodiazepines counteract rostral anterior cingulate cortex activation induced by cholecystokinin-tetrapeptide in humans. Biol Psychiatry 73: 337-344.

Maddock RJ, Casazza GA, Buonocore MH, Tanase C (2011). Vigorous exercise increases brain lactate and Glx (glutamate + glutamine): a dynamic 1H-MRS study. Neuroimage 57: 1324-1330.

Malizia AL, Cunningham VJ, Bell CJ, Liddle PF, Jones T, Nutt DJ (1998). Decreased brain GABA(A)-benzodiazepine receptor binding in panic disorder: preliminary results from a quantitative PET study. Arch Gen Psychiatry 55: 715-720.

Martin EI, Ressler KJ, Binder E, Nemeroff CB (2010). The neurobiology of anxiety disorders: brain imaging, genetics, and psychoneuroendocrinology. Clin Lab Med 30: 865-891.

Mashhoon Y, Janes AC, Jensen JE, Prescot AP, Pachas G, Renshaw $\mathrm{PF}$ et al (2011). Anterior cingulate proton spectroscopy glutamate levels differ as a function of smoking cessation outcome. Prog Neuropsychopharmacol Biol Psychiatry 35: 1709-1713.

Mathew SJ, Amiel JM, Coplan JD, Fitterling HA, Sackeim HA, Gorman JM (2005). Open-label trial of riluzole in generalized anxiety disorder. Am J Psychiatry 162: 2379-2381.

Nothdurfter C, Baghai TC, Schüle C, Rupprecht R (2012). Translocator protein $(18 \mathrm{kDa})$ (TSPO) as a therapeutic target for anxiety and neurologic disorders. Eur Arch Psychiatry Clin Neurosci 262(Suppl 2): 107-112.

Otto MW, Tolin DF, Simon NM, Pearlson GD, Basden S, Meunier SA et al (2010). Efficacy of d-cycloserine for enhancing response to cognitive-behavior therapy for panic disorder. Biol Psychiatry 67: 365-370.

Pfleiderer B, Michael N, Erfurth A, Ohrmann P, Homann U, Wolgast $M$ et al (2003). Effective electroconvulsive therapy reverses glutamate/glutamine deficit in the left anterior cingulum of unipolar depressed patients. Psychiatr Res Neuroimaging 122: $185-192$.

Pfleiderer B, Ostermann J, Michael N, Heindel W (2002). Visualization of auditory habituation by fMRI. Neuroimage 17: 1705-1710.

Phan KL, Fitzgerald DA, Cortese BM, Seraji-Bozorgzad N, Tancer ME, Moore GJ (2005). Anterior cingulate neurochemistry in social anxiety disorder: 1H-MRS at 4 Tesla. Neuroreport 16: 183-186.

Pittenger C, Coric V, Banasr M, Bloch M, Krystal JH, Sanacora G (2008). Riluzole in the treatment of mood and anxiety disorders. CNS Drugs 22: 761-786.

Provencher SW (1993). Estimation of metabolite concentrations from localized in vivo proton NMR spectra. Magn Reson Med 30: 672-679.

Ressler KJ, Rothbaum BO, Tannenbaum L, Anderson P, Graap K, Zimand $\mathrm{E}$ et al (2004). Cognitive enhancers as adjuncts to psychotherapy: use of D-cycloserine in phobic individuals to facilitate extinction of fear. Arch Gen Psychiatry 61: 1136-1144.

Riaza Bermudo-Soriano C, Perez-Rodriguez MM, VaqueroLorenzo C, Baca-Garcia E (2011). New perspectives in glutamate and anxiety. Pharmacol Biochem Behav 100: 752-774.

Rogan MT, Staubli UV, LeDoux JE (1997). Fear conditioning induces associative long-term potentiation in the amygdala. Nature 390: 604-607.

Roy-Byrne PP, Stang P, Wittchen HU, Ustun B, Walters EE, Kessler RC (2000). Lifetime panic-depression comorbidity in the National Comorbidity Survey. Association with symptoms, impairment, course and help-seeking. Br J Psychiatry 176: 229-235.

Rupprecht R, Papadopoulos V, Rammes G, Baghai TC, Fan J, Akula $\mathrm{N}$ et al (2010). Translocator protein (18 kDa) (TSPO) as a therapeutic target for neurological and psychiatric disorders. Nat Rev Drug Discov 9: 971-988.

Rupprecht R, Rammes G, Eser D, Baghai TC, Schüle C, Nothdurfter $\mathrm{C}$ et al (2009). Translocator protein $(18 \mathrm{kD})$ as target for anxiolytics without benzodiazepine-like side effects. Science 325: 490-493.

Salt TE, Eaton SA (1996). Functions of ionotropic and metabotropic glutamate receptors in sensory transmission in the mammalian thalamus. Prog Neurobiol 48: 55-72.

Sanacora G, Mason GF, Rothman DL, Behar KL, Hyder F, Petroff OA et al (1999). Reduced cortical gamma-aminobutyric acid levels in depressed patients determined by proton magnetic resonance spectroscopy. Arch Gen Psychiatry 56: 1043-1047.

Schunck T, Erb G, Mathis A, Gilles C, Namer IJ, Hode Y et al (2006). Functional magnetic resonance imaging characterization of CCK-4-induced panic attack and subsequent anticipatory anxiety. Neuroimage 31: 1197-1208.

Sheehan DV, Lecrubier Y, Harnett-Sheehan K, Janavs J, Weiller E, Bonara LI et al (1997). Reliability and validity of the MINI International Neuropsychiatric Interview (M.I.N.I.): according to the SCID-P. Eur Psychiatry 12: 232-241.

Shlik J, Aluoja A, Vasar V, Vasar E, Podar T, Bradwejn J (1997). Effects of citalopram treatment on behavioural, cardiovascular and neuroendocrine response to cholecystokinin tetrapeptide challenge in patients with panic disorder. J Psychiatry Neurosci 22: $332-340$.

Strohle A, Romeo E, di Michele F, Pasini A, Hermann B, Gajewsky $\mathrm{G}$ et al (2003). Induced panic attacks shift gamma-aminobutyric acid type A receptor modulatory neuroactive steroid composition in patients with panic disorder: preliminary results. Arch Gen Psychiatry 60: 161-168.

Strohle A, Romeo E, Di Michele F, Pasini A, Yassouridis A, Holsboer $\mathrm{F}$ et al (2002). GABA(A) receptor-modulating neuroactive steroid composition in patients with panic disorder before and during paroxetine treatment. Am J Psychiatry 159: 145-147.

Stutzmann JM, Cintrat P, Laduron PM, Blanchard JC (1989). Riluzole antagonizes the anxiogenic properties of the beta-carboline FG 7142 in rats. Psychopharmacology (Berl) 99: 515-519.

Walker DL, Davis M (2002). The role of amygdala glutamate receptors in fear learning, fear-potentiated startle, and extinction. Pharmacol Biochem Behav 71: 379-392.

White KS, Barlow DH (2002). Panic disorder and agoraphobia. In: Barlow DH (eds) Anxiety and its Disorders. The Guilford Press: New York, London, UK, pp 328-379.

Zwanzger P, Domschke K, Bradwejn J (2012). Neuronal network of panic disorder: the role of the neuropeptide cholecystokinin. Depress Anxiety 29: 762-774.

Zwanzger P, Eser D, Aicher S, Schule C, Baghai TC, Padberg F et al (2003). Effects of alprazolam on cholecystokinin-tetrapeptideinduced panic and hypothalamic-pituitary-adrenal-axis activity: a placebo-controlled study. Neuropsychopharmacology 28: 979-984.

Zwanzger P, Rupprecht R (2005). Selective GABAergic treatment for panic? Investigations in experimental panic induction and panic disorder. J Psychiatry Neurosci 30: 167-175. 